\title{
The identification of basic problems on the form and functioning of the family in Albanian
} society

\author{
Maria DOJCE \\ PhD Candidate \\ Department of Social Science \\ University Fan S. Noli, Korçë-Albania \\ E-mail: maria.dojce@gmail.com
}

\begin{abstract}
In this article the author has presented the form of Albanian family, the crucial problems and general mentality. Nowadays, the modern societies have built a new form of family, nuclear family or close family. This kind of family is much functional regarding the structure of the society, because we know that family relationship is very important for socialization process, and education of citizenship. On the other hand, the global culture and social development have generated importance of nuclear family in societies under transition, too. Albanian society has developed some forms of modernity but institution of family has not the clear form of the nuclear family. The tradition and psycho-social aspects have been the most difficult barriers for transformation of family. Some other issues discussed in this article are conservative mentality, the cultural heritage, the norms and values under the global inflection. In addition, the last approaches of the family institution in Albanian society have shown the influence of the issues mentioned above, but the rural regions have major problems yet.
\end{abstract}

Key words: nuclear family, structure, socialization, culture, global.

\section{Introduction}

It is already known that to have a healthy society is needed a healthy family1. The structure of the family, the same as the social structure is permanently changing throughout the globe. Referring to the global developments of the family institution it is visible that the dynamic and diversity of the family patterns is high. But, in this article will be argued about the main forms of the institution of family in the Albanian society.

It is well known that Albania is a post-communist country, which is trying to rebuild a democratic and civil society. Due to this reason, in the focus of this study will be the social developments of the past two decades. Since the very beginnings of the democratization of Albanian society, all the social and administrative institutions underwent to the functional alienation process (the transition). in this context, the institution of family is no exception. Today, after about 22 years of the democratic society, having in focus the civic cultivation of the individual and society itself, is identified that there are exactly the forms of the family structure those that play an important role in the social well-functioning.

In addition, two postmodernist's sociologists Delphy and Leonard wrote: 'the family is patriarchal and hierarchical institution through the men dominate and exploit women. But, the modern society generated new forms of family so they highlight many ways in which the family can produce or reinforce inequalities between women and men2'.

The Albanian family has been characterized by the normative traditional form, conservative and sub-cultural. This has resulted with the change of family structure, regarding its performance, according to the region, geographical position and psycho-social conditions.

The main forms of the family have been: patriarchal norms, monogamous marriage with consent from both parties accepted and adopted by the society and institutions, and the tendency of the cohabitation of more than two generations within a

1 Fromm Erich; The Sane Society, Tiranë 2003, p. 57

2 Harallambos Michael: Sociology themes and Perspectives, Collins 2007, p. 468 
family (i.e. young couple, children and the parents of one of the partners). The rights of women in decision making have been limited and the social division of labour have been accomplished according to the gender roles 1.

Mothers are those who bear the major share of housework and childcare.

While, in modern societies (I mean the western societies), the nuclear family results as one of the most functional family institution. in this kind of families is enabled the rationality of: a) parent-child relationship, b) relationship in marriage and c) tribal relations. Principles of community socialization are qualified as the key contributors of a healthy society Erich Fromm2.

But, in this article we will see what happens today with the institution of the family in this society and what the main problems that generate non-stability of this institution are.

\section{Methodology}

This study is of an analytic-empiric approach, which describes the actuality of Albanian family in its structural, functional and applicative dimension.

The study has been conducted through the following presented instruments:

Target group have been the inhabitants of Korça region.

The survey is made through questionnaires.

The Sample has included 250K respondents.

The by random quantitative method is used.

Interpretation of data is made through the Soft Program SPSS 17.

The purpose of this study is to emphasize the normative and descriptive importance of the institution of the nuclear family in socialization and orientation of new generations towards the democratic and civil principles. This then leads to social and institutional well-functioning.

The research question of this study is: what are the socio-psychological conditions that advance or prevent consolidation of the nuclear family in Albanian society?

Defeat of the nuclear family in Albania

From the data collected in the region of Korça results that nuclear family (closed), are about $38.9 \%$ while the extended family (traditional) are about $61.1 \%$. These figures show that we still have the dominance of traditional family where the young couple cohabits with the older generation and children that get born.

Some of the causes that do not favour the integration of the extended family to nuclear family, regardless of the democratization process which is based on the civic norms and human rights, have to do mainly with social policy and mentality inherited. Thus, $28 \%$ of respondents consider that they are dependent on common household economy and this does not enable the economic independence of the new couple and weakens the living material conditions. While $45.5 \%$ of the respondents believe that in the Albanian mentality is rooted addiction that parents have on children (especially males), where the sons get "educated" since the early stages of childhood that they should take care and live with their parents at all stages of their life. in this way the son that doesn't live with his parents when married get prejudiced by his relatives and the social opinion as a deviant and relentless person who has abandoned his parents. The earlier studies show the interesting data where specified the mentality of traditional society about the sons 3 .

Another category of about $26.5 \%$ respondents stated that it is their choice to cohabit in an open family, as this choice of cohabitation facilitates their primary responsibilities for the family, enables tracking and productive implementation of the work outside the family and provides better care for growing of the children.

However, from the data collected it is visible that urban centres are more rational in organization of the family and have a growing trend of the closed family.

In young couples $48.5 \%$ wish to have the first child made, $21.5 \%$ wish to have the first child female and $30 \%$ of the respondents say that the gender of the child does not matter.

1 Durkheim Emil: The devision of Labor in Society, NY 1997, p. 151

2 Fromm Erich; The Sane Society,Routledge 2003, p.

3 Dervishi Zyhdi: Flirtation with wound, Tiranë 2008, p.22 
Family planning is another supportive element for consolidation of the nuclear family structure in Albanian society.

In addition, we can say that Albanian family has an alternative form between traditional and modern elements. in this contact Nicholson wrote; alternative families are often better than traditional ones for the women who live in them1

\section{Advantages and disadvantages of these reality}

In the open families the moral and emotional solidarity remain the mechanical forms dominated by the gender stereotype and prejudice from the others. in this way the individualism and independence of individual continue to have lower limits of application.

Children are socialized under the mentality that they are the property of their parents and form dual personalities. Patterns of behaviour have ambiguous shape because parents are not the only guiders in the family but very often the models perceived from them are in conflict with the mentality of the third generation. This situation confuses the model and the value norms of behaviour which should be clear for the child in order to form his own personality and orientation towards social relations.

In this way, the child gets influenced to create dual personality which is reflected in the relationships that he builds in the future, where are visibly recognised the lack of correctness, low level of responsibility on the performed actions, the lack of the value of work and very often are detected irrational relationships between parents and children.

Also, in extended families usually the family is run by the third generation, and this brings the young couples losing their intimacy and often marital crisis within relationships are caused. Thus, it is seen that in the open families the spouses lose easily the respect for each other, tend to blame each other more easily in situations of conflict and above all the consolidation of the successful marriage get faded.

In this context, Erich Fromm says: "Relationship of the mother with her child is totally paradoxical, and in a kind of sense tragic. Children require from their mothers love and it is exactly this love that should help the child to grow and be separated from the mother, to become fully independent. It is easy for every mother to love her child, but to love your child and at the same time to allow him to leave, is a task that the majority of mothers are not able to meet2.

In the closed families (nuclear family), the couples' relationship preserves coherence and long life. The responsibility of the spouses on the progress of the family and the care for the kids preserves clear affective forms.

In these conditions of the nuclear family get strengthened the parent-child relationship, and parents can exercise their parenting more easily. in this situation, the child has clear models of values and norms and is keen to create an individual personality (his Self).

Also, the roles in the family are easily determinable and participation of the whole family members becomes a necessity.

The nuclear family minimizes the gender stereotypes and promotes gender equality, because all the members of the family have the opportunity to contribute in the management and welfare of the family itself.

Another important aspect of the nuclear family is the role of the children in decision-making and collective solidarity. Fairness, tolerance and respect are some of the highest values in children who are socialized in nuclear families. These forms of socialization enable strengthening of individualism, rationality of social interaction and consolidate cultivation of a personal and public culture. This means limiting of the prejudices of the social mentality and strengthening of the individual personality ignoring the parasite forms of mentality.

But, on the other hand, this form of family organization strengthens the relationships between generations, as the accountability to the third generation gets increased and the respect between generations gets enhanced. This means that the conflicts between generations get avoided and the individual finds his space of the social performance. in this way individual gets socialized consistently with the global culture norms and the civic development and contributes to a healthier society.

\section{Conclusions}

1 Harallambos Michael: Sociology themes and Perspectives, Collins 2007, p. 471

2 Fromm Erich: The Sane Society, Tiranë 2012, p. 37. 
Albania continues to be a transitional society where consolidation of the genuine democratic forms grows more and more the demand for a civil society with norms and values in line with the global developments. Normally, this means building of a healthy society which has its genesis to the institution of the family. This institution roots and matures the principles and civic values since the early stages of human life through socialization processes. Thus it is noted that during the two last decades the family institution is in a rapid transformation, where is strictly preserved the customary traditions inherited from centuries but on the other hand are being consolidated even the new forms of operation of this institution.

However, to consolidate a modern society with norms, values, principles and social character should be invested in cultivation and enrichment of the cultural aspect. It is exactly the culture which may lessen traditional conservatism and can give breathing to the civic principles.

Another challenge, which remains current in Albanian society, is trans-institutional cooperation to facilitate the stages of socialization of young generations in accordance with the principles of contemporary society. Here the author refers to the cooperation of the family institution with the educational system so that normative and value models do not have large discrepancies.

The ambiguity of women' role in the family is another situation in the process of the family transition because the position of women in family and society in general has been hardly changed during the last decades.

\section{References}

Fromm Erich: The sane society, Tiranë 2012. (The text is translated into Albanian language).

Harallambos Michael: Sociology Themes and Perspectives 7th edition, Collins 2007.

Durkheim Emil: The division of labor in Society, New York 1997.

Durkeim Emil: The lessons of Sociology, Tiranë2004.

Giddens Anthony: Sociology, Soros, Tiranë 1997.

Dervishi Zyhdi: Flirtation with wound, Tiranë 2010.

Dervishi Zyhdi: Between the rams of Albanian culture, Tiranë 2013.

Fuga Artan; Dervishi Zyhdi: Between village and global Citizenship, Tiranë 2010.

Buscaglia Leo: Living, Loving and Learning, Tiranë 2010.

Williams Raymond: The sociology of Culture, Chicago Press 1995.

\section{References of Internet}

[1] http//sites.google.com/site/sociologyas/families-households/types-of-families

[2] Kurt Lewin: The Origins of Action Research, Educational Action Research, 1:1,

[3] 7-24 to link to this article: http://dx.doi.org/10.1080/0965079930010102

[4] file:///C:/Documents\%20and\%20Settings/user/My\%20Documents/Downloads/02\%20ARTICULO\%202SOCIALIZATION\%20TACTICS.pdf 


\section{Annex}

Tables and charts

The percentage of family types

\section{The family types}

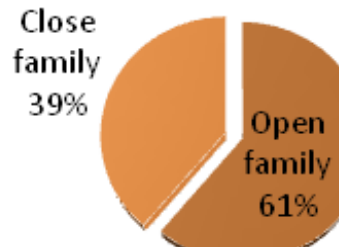

\section{Gender stereptypes}

$\square$ 1st child male $\quad$ to have a child male

$\square$ Indifferent at gender

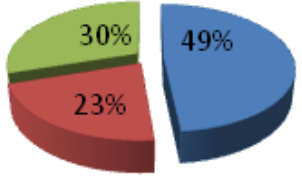

The integration of family elements

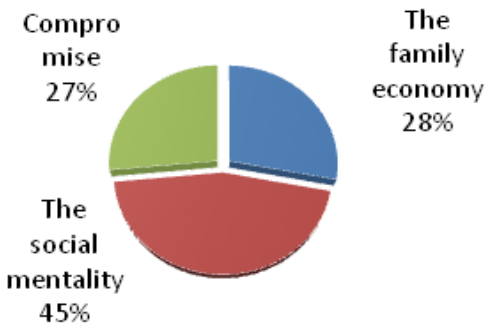

